\title{
CORRIGENDUM
}

\section{Poisson's ratio and modern materials}

G. N. Greaves, A. L. Greer, R. S. Lakes and T. Rouxel

Nature Materials 10, 823-837 (2011); published online 24 October 2011; corrected after print 24 October 2011.

In the print version of this Review, in Box 2, 'an order of magnitude' should read 'orders of magnitude' in the sixth sentence from the end. In the caption for Fig. 1, the credit given for part a actually related to part b. In Fig. $5 c$, the arrow labels for the inner and outer core are transposed. In the Acknowledgements, C. Kurkjian is spelt incorrectly. The online versions are correct. 